\title{
A New Depside Isolated from the Bark of Rauwolfia mattfeldiana
}

\author{
Ivo J.C. Vieira ${ }^{a}$, Christian M.P. Cecchi ${ }^{a}$, Leda Mathias ${ }^{a}$, \\ Raimundo Braz-Filho ${ }^{a}$, and Edson Rodrigues-Filho ${ }^{b}$ \\ ${ }^{a}$ Setor de Produtos Naturais-CCTA/CCT, Universidade Estadual do Norte Fluminense, \\ Campos, 28015-620 Rio de Janeiro - RJ, Brazil \\ ${ }^{b}$ Departamento de Química da Universidade Federal de São Carlos \\ 13560-905 São Carlos - SP, Brazil
}

Received: August 13, 1997

\begin{abstract}
Do extrato hexânico da casca do caule de Rauwolfia mattfeldiana Markgr. (Apocynaceae) foram isolados um novo depsídeo (1, 4'-O-metilartonioato de metila), a 1-hidroxi-3,6-dimetoxi-8metilxantona (4), lupeol (5), sitosterol (6) e estigmasterol (7). As estruturas destas substâncias foram elucidadas pela análise de seus dados espectrais. RMN bidimensional (2D) foi utilizada para definir a estrutura e garantir a atribuição inequívoca dos deslocamentos químicos dos átomos de hidrogênio e carbono do novo depsídeo.

From the hexane extract from stem bark of Rauwolfia mattfeldiana Markgr. (Apocynaceae) a new depside (1, methyl 4'-O-methylarthonioate), along with 1-hydroxy-3,6-dimethoxy-8-methylxanthone (4), lupeol (5), sitosterol (6) and stigmasterol (7) were isolated. The structures of these natural products were elucidated by spectral data analysis. 2D NMR experiments were used to establish the structure and the complete hydrogen and carbon chemical shift assignments of the new depside.
\end{abstract} data

Keywords: Rauwolfia mattfeldiana, Apocynaceae, depside, xanthone, terpenoids, spectral

\section{Introduction}

In the course of our phytochemical investigations on Brazilian plants, we studied the constituents of Rauwolfia mattfeldiana Markgr., Apocynaceae. The genus Rauwolfia is known for its diversity and abundance of bioactive alkaloids ${ }^{1}$, which provided additional interest to undertake the chemical investigation.

The new depside methyl 4'-O-methylarthonioate (1), a derivative of arthonioic acid [2, isomer of microphyllinic acid (3) $]^{2,3}$, was isolated from $n$-hexane extract of the stem bark, along with the known 1-hydroxy-3,6-dimethoxy-8methylxanthone (4, lichexanthone), lupeol (5), sitosterol (6) and stigmasterol (7).

The polyketides 2, 3 and $\mathbf{4}$ are classified as lichen (symbiont consisting of a fungus and an algae growing together in a composite structure) ${ }^{4}$ bioproducts. The depsides arthonioic acid (2) and microphyllinic acid (3) were isolated from Arthonia impolita ${ }^{2}$ and Centaria collata ${ }^{3}$, respectively, and lichexanthone (4) from Parmelia formanosa, Pertusaria sulphurata and Anthocleista djalonensis ${ }^{5}$. The structures of the natural products $1,4,5,6$ and 7 were deduced on the basis of spectral data, including 2D NMR techniques (HMQC- ${ }^{1} J_{\mathrm{CH}}$ and HMBC- ${ }^{\mathrm{n}} J_{\mathrm{CH}}, \mathrm{n}=2$ and 3).

\section{Results and Discussion}

The known natural products lichexanthone (4), lupeol (5), sitosterol (6) and stigmasterol (7), were identified mainly by their ${ }^{1} \mathrm{H}$ - and ${ }^{13} \mathrm{C}$-NMR spectral data, including comparison with literature values $\left(4^{6}, 5^{7}, 6\right.$ and $\left.7^{8}\right)$.

The IR spectrum of $\mathbf{1}$ showed absorption bands for carbonyl ketone $\left(v 1715 \mathrm{~cm}^{-1}\right)$, conjugated carbonyl ester group $\left(v 1720 \mathrm{~cm}^{-1}\right)$ and aromatic ring $(v 1597$ and $\left.1499 \mathrm{~cm}^{-1}\right)$. The molecular formula was inferred to be $\mathrm{C}_{31} \mathrm{H}_{40} \mathrm{O}_{9}$ based on the 40 hydrogen and 31 carbon signals 


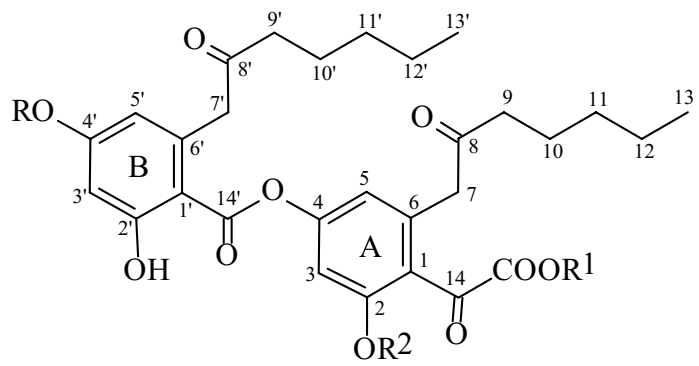<smiles>COc1cc(C)c2c(=O)c3c(O)cc(OC)cc3oc2c1</smiles>

$1 \mathrm{R}=\mathrm{R} 1=\mathrm{R} 2=\mathrm{Me}$

$2 \mathrm{R}=\mathrm{R} 1=\mathrm{H}, \mathrm{R} 2=\mathrm{Me}$

$3 \mathrm{R}=\mathrm{Me}, \mathrm{R} 1=\mathrm{R} 2=\mathrm{H}$

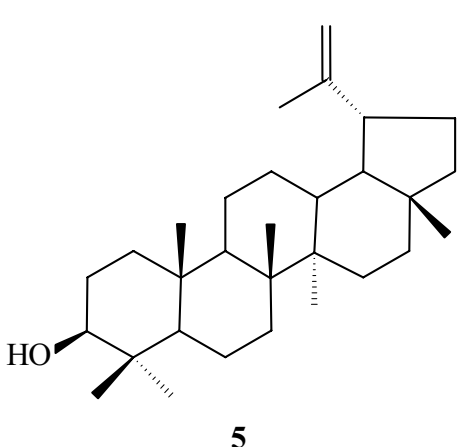

5

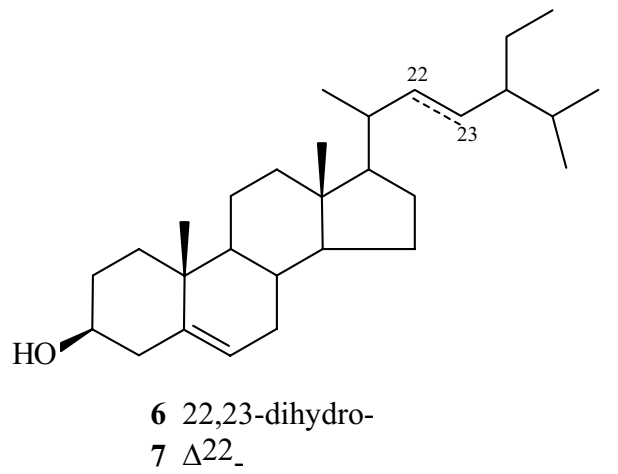

observed in the ${ }^{1} \mathrm{H}$ - and ${ }^{13} \mathrm{C}$ - (PND and DEPT) NMR spectra (Table 1), respectively. This deduction was supported by the presence in the mass spectrum of peaks at $\mathrm{m} / \mathrm{z}$ $294\left(\mathrm{C}_{16} \mathrm{H}_{22} \mathrm{O}_{5}\right)$ and $262\left(\mathrm{C}_{15} \mathrm{H}_{18} \mathrm{O}_{4}\right)$ which were presumed to be caused by fragments $1 \mathbf{a}$ and $\mathbf{1 b}$ (Scheme 1), generated from the molecular ion $\left[\mathrm{C}_{31} \mathrm{H}_{40} \mathrm{O} 9, \mathrm{~m} / \mathrm{z} 556\left(\mathrm{M}^{+}\right.\right.$, absent)] after aromatic ortho-substituents fragmentation and hydrogen rearrangement (Scheme 1). The hydrogenation pattern for each ${ }^{13} \mathrm{C}$ signal was deduced by comparative analysis of the proton noise decoupled (PND) and distortiorless enhancement by polarization transfer (DEPT) ${ }^{9}$ spectra (Table 1). The presence of three methoxyl $\left[\delta v_{\mathrm{H}} 3.82(\mathrm{~s}), 3.84\right.$ $(\mathrm{s})$ and $3.87(\mathrm{~s})]$ and a chelatogenic hydroxyl $\left[\delta_{\mathrm{H}} 11.26(\mathrm{~s})\right]$ groups was confirmed by ${ }^{1} \mathrm{H}-\mathrm{NMR}$ spectrum. These data, in combination with ${ }^{13} \mathrm{C}$-NMR spectra (Table 1) and the peaks at $\mathrm{m} / \mathrm{z} 294(7 \%)$ and $262(11 \%)$ observed in the EI mass spectrum (Scheme 1), were used to deduce the two moieties of the molecule, each sustaining meta aromatic hydrogens $\left[\delta_{\mathrm{H}} 6.59(d, J=1.9 \mathrm{~Hz}, \mathrm{H}-3), 6.56(d, J=1.9\right.$ Hz, H-5); 6.49 ( $d, J=2.5 \mathrm{~Hz}, \mathrm{H}-3$ '), $6.29(d, J=2.5 \mathrm{~Hz}$, H-5'); two $\mathrm{AB}$ systems]. The presence of two $\mathrm{CH}_{2} \mathrm{COCH}_{2} \mathrm{CH}_{2} \mathrm{CH}_{2} \mathrm{CH}_{2} \mathrm{CH}_{3}$ chains was recognized by the chemical shifts and multiplicities of the following signals clearly observed in the ${ }^{1} \mathrm{H}$ NMR spectrum: two benzylic and $\sigma$-carbonyl methylene hydrogens $\left[\delta_{\mathrm{H}} 3.69(s\right.$, $2 \mathrm{H}-7)$ and $\left.4.06\left(s, 2 \mathrm{H}-7^{\prime}\right)\right]$, two $\alpha$-carbonyl methylenes bound to $\beta-\mathrm{CH}_{2}\left[\delta_{\mathrm{H}} 2.43(t, J=7.4 \mathrm{~Hz}, 2 \mathrm{H}-9)\right.$ and $2.41(t$, $J=7.5 \mathrm{~Hz}, 2 \mathrm{H}-9$ ') $]$ and two methyl groups attached to $\mathrm{CH}_{2}$
$\left[\delta_{\mathrm{H}} 0.88\left(t, J=6.8 \mathrm{~Hz}, 3 \mathrm{H}-13\right.\right.$ or $3 \mathrm{H}-13^{\prime}$ and $0.83(t, J=7.1$ $\mathrm{Hz}, 3 \mathrm{H}-13^{\prime}$ or $\left.\left.3 \mathrm{H}-13\right)\right]$. This proposition was corroborated by the ${ }^{13} \mathrm{C}$-NMR spectra (Table 1: ten signals of methylene carbon atoms and two of methyl groups) and by EI mass spectrum, in which the peaks at $m / z 99(56 \%)$ and $71(66 \%)$ were attributed to fragments $\mathbf{1 c}$ and 1d, respectively (Scheme 1). The unambiguous location of the substituents at the aromatic rings and the assignment of the ${ }^{1} \mathrm{H}$ - and ${ }^{13} \mathrm{C}$-NMR chemical shifts were established by heteronuclear ${ }^{1} \mathrm{H} \mathrm{x}{ }^{13} \mathrm{C}-\mathrm{COSY}-{ }^{\mathrm{n}} J_{\mathrm{CH}}\left[\mathrm{n}=1, \operatorname{HMQC}\left({ }^{1} J_{\mathrm{CH}}\right) ; \mathrm{n}=2\right.$ and 3, HMBC $\left({ }^{2} J_{\mathrm{CH}}\right.$ and $\left.\left.{ }^{3} J_{\mathrm{CH}}\right)\right] 2 \mathrm{D}$ shift-correlated NMR spectra $^{10}$, after assignment of the signals corresponding to quaternary, methine, methylene and methyl carbon atoms by comparative analysis of the PND- and DEPT- ${ }^{13} \mathrm{C}-\mathrm{NMR}$ spectra (Table 1) along with application of the usual shift parameters ${ }^{9}$. The starting point to deduce the substitution pattern for aromatic ring $\mathrm{B}$ was the singlet signal of the chelatogenic hydroxyl group $\left(\delta_{\mathrm{H}} 11.26\right)$ at $\mathrm{C}-2$ '. This group provides an example where the cross peaks corresponding to $\mathrm{OH}$ signal $\left(\delta_{\mathrm{H}} 11.26\right)$ and ${ }^{13} \mathrm{C}-\mathrm{NMR}$ signals from two quaternary carbons at $\delta_{\mathrm{c}} 104.34\left(\mathrm{C}-1,{ }^{3} J_{\mathrm{CH}}\right)$ and 166.52 $\left(\mathrm{C}-2{ }^{\prime},{ }^{2} J_{\mathrm{CH}}\right)$ and one methine carbon at $\delta_{\mathrm{C}} 100.10(\mathrm{CH}-3$ ', ${ }^{3} J_{\mathrm{CH}}$ ) were observed in the $\mathrm{HMBC}$ spectrum, allowing identification of the signals of C-1', C-2' and C-3'. The signal of $\mathrm{C}-1{ }^{\prime}\left(\delta_{\mathrm{C}} 104.34\right)$ also revealed cross peaks to ${ }^{1} \mathrm{H}$ frequencies corresponding to $\mathrm{H}-3{ }^{\prime}\left(\delta_{\mathrm{H}} 6.49,{ }^{3} J_{\mathrm{CH}}\right), \mathrm{H}-5{ }^{\prime}\left(\delta_{\mathrm{H}}\right.$ $\left.6.29,{ }^{3} J_{\mathrm{CH}}\right)$ and $2 \mathrm{H}-7^{\prime}\left(\delta_{\mathrm{H}} 4.06,{ }^{3} J_{\mathrm{CH}}\right)$. The signals of $2 \mathrm{H}-7^{\prime}$ $\left(\delta_{\mathrm{H}} 4.06\right)$ and $2 \mathrm{H}-9^{\prime}\left(\delta_{\mathrm{H}} 2.41\right)$ showed correlations with ${ }^{13} \mathrm{C}$ 


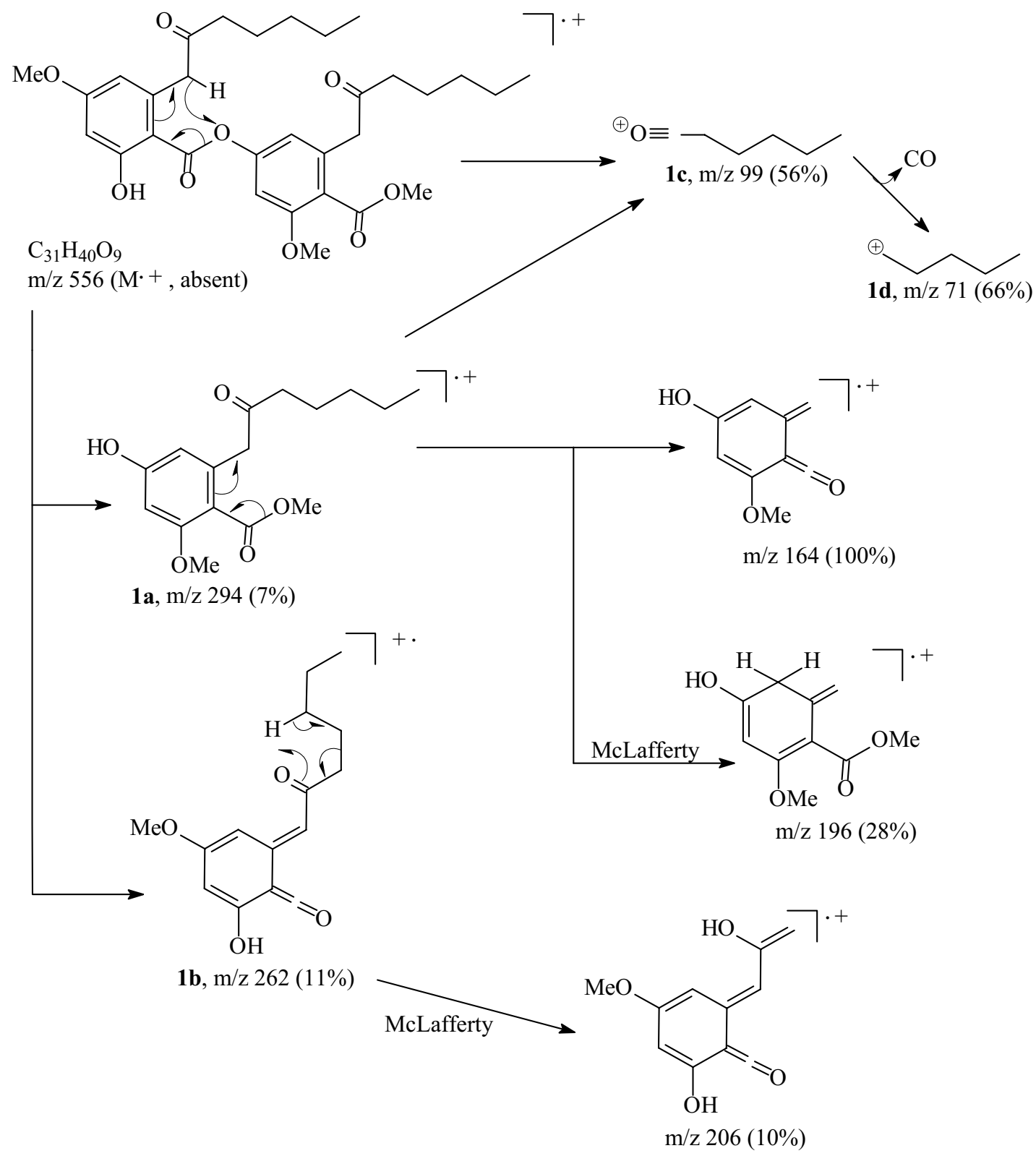

Scheme 1. Proposed fragmentation mechanisms of 1 (only peaks classified as principals).

signal at $\delta_{\mathrm{C}} 207.34\left(\mathrm{C}-8,{ }^{2} J_{\mathrm{CH}}\right)$. Working along the molecule in this fashion, in combination with analysis of the HMQC $\left({ }^{1} J_{\mathrm{CH}}\right)$ spectrum, it was possible to establish the substitution patterns of the aromatic rings and to assign the ${ }^{1} \mathrm{H}$ - and ${ }^{13} \mathrm{C}$ - NMR signals, as summarized in Table 1.

Thus, the structure of the new depside isolated from hexane extract of Rauwolfia mattfeldiana was established as methyl 4'-O-methylarthonioate (1). This natural product together with lichexanthone (4) are polyketide classified due to being produced by the secondary metabolism of lichens ${ }^{4}$. Consequently, it appears probable that the stem bark from the specimen of Rauwolfia mattfeldiana used in this chemical investigation was in association with this symbiont.

Finally, our attention was directed to the mass spectrum of the depside 1. A proposal for the fragmentation patterns justifying the major peaks is described in Scheme 1.

\section{Experimental}

\section{General experimental procedures}

M.p. are uncorrected. ${ }^{1} \mathrm{H}-(400 \mathrm{MHz})$ and ${ }^{13} \mathrm{C}-(100$ $\mathrm{MHz}$ ) NMR spectra were recorded in $\mathrm{CDCl}_{3}$ using a Bruker ARX-400 spectrometer; chemical shifts are quoted in $\delta$ units relative to TMS as the internal standard. Coupling constants $(J)$ are expressed in Hz. The mass spectrum was 
measured in a VG Platform II-Fisons instrument using electron impact (EI) at $70 \mathrm{eV}$. Recycling HPLC was carried out using a Asahipak GS-310P column (21.5 mm x 50.0 $\mathrm{cm} ; 13 \mu \mathrm{m}), \mathrm{MeOH} / \mathrm{CHCl}_{3}(7: 3)$ as mobile phase, flow rate $3.0 \mathrm{~mL} / \mathrm{min}$ and UV detection $254 \mathrm{~nm}$.
Plant material

Aerial parts of Rauwolfia mattfeldiana Markgr., Apocynaceae family, were collected in September 1996 at Reserva Florestal de Linhares, Espírito Santo State, Brazil,

Table 1. ${ }^{1} \mathrm{H}-(400 \mathrm{MHz})$ and ${ }^{13} \mathrm{C}-(100 \mathrm{MHz}) \mathrm{NMR}$ spectral data for depside 1 in $\mathrm{CDCl}_{3}$ and TMS as internal standard. The chemical shifts are in $\delta$ (ppm) and coupling constants $(J$, in parenthesis) in Hz.*

\begin{tabular}{|c|c|c|c|c|}
\hline & & HMQC & & HMBC \\
\hline $\mathrm{C}$ & $\delta_{\mathrm{C}}$ & $\delta_{\mathrm{H}}$ & ${ }^{2} J_{\mathrm{CH}}$ & ${ }^{3} J_{\mathrm{CH}}$ \\
\hline 1 & 121.79 & - & & $\mathrm{H}-3, \mathrm{H}-5,2 \mathrm{H}-7$ \\
\hline 2 & 158.37 & - & $\mathrm{H}-3$ & MeO-2 \\
\hline 4 & 151.26 & - & H-3, H-5 & \\
\hline 6 & 135.39 & - & $2 \mathrm{H}-7$ & \\
\hline 8 & 206.52 & - & $2 \mathrm{H}-7$ & \\
\hline 14 & 169.07 & - & & $\mathrm{MeO}-14$ \\
\hline 1 & 104.34 & - & & H-3', H-5', 2H-7', HO-2' \\
\hline $2^{\prime}$ & 166.52 & - & HO-2' & \\
\hline 4 ' & 164.90 & - & & $\mathrm{MeO}-4$ ' \\
\hline $6^{\prime}$ & 138.93 & - & $2 \mathrm{H}-7$ & \\
\hline $8^{\prime}$ & 207.34 & - & $2 \mathrm{H}-7^{\prime}, 2 \mathrm{H}-9$ ' & \\
\hline $14^{\prime}$ & 167.44 & - & & \\
\hline \multicolumn{5}{|l|}{$\mathrm{CH}$} \\
\hline 3 & 104.50 & $6.59(d, J=1.9)$ & & H-5 \\
\hline 5 & 116.16 & $6.56(d, J=1.9)$ & & $\mathrm{H}-3,2 \mathrm{H}-7$ \\
\hline $3^{\prime}$ & 100.10 & $6.49(d, J=2.5)$ & & HO-2', H-5' \\
\hline 5 & 113.34 & $6.29(d, J=2.5)$ & & H-3', 2H-7' \\
\hline \multicolumn{5}{|l|}{$\mathrm{CH}_{2}$} \\
\hline 7 & 47.50 & $3.69(s)$ & & H-5 \\
\hline 9 & 42.47 & $2.43(t, J=7.4)$ & $2 \mathrm{H}-10$ & \\
\hline 10 & $23.30^{\mathrm{a}}$ & $1.54(\mathrm{~m})$ & $2 \mathrm{H}-9$ & \\
\hline 11 & $31.26^{\mathrm{b}}$ & $1.21(\mathrm{~m})$ & $2 \mathrm{H}-10,2 \mathrm{H}-12$ & $2 \mathrm{H}-9,3 \mathrm{H}-13$ \\
\hline 12 & $22.41^{\mathrm{c}}$ & $1.18(m)$ & $3 \mathrm{H}-13,2 \mathrm{H}-11$ & \\
\hline $7^{\prime}$ & 51.22 & $4.06(s)$ & & $\mathrm{H}-5$ ' \\
\hline $9^{\prime}$ & 42.16 & $2.41(t, J=7.5)$ & $2 \mathrm{H}-10$ & \\
\hline $10^{\prime}$ & $23.38^{\mathrm{a}}$ & $1.54(\mathrm{~m})$ & 2H-9 & \\
\hline $11^{\prime}$ & $31.36^{\mathrm{b}}$ & $1.21(\mathrm{~m})$ & $2 \mathrm{H}-10^{\prime}, 2 \mathrm{H}-12^{\prime}$ & 2H-9', 3Н-13' \\
\hline $12^{\prime}$ & $22.41^{\mathrm{c}}$ & $1.18(\mathrm{~m})$ & $3 \mathrm{H}-13^{\prime}, 2 \mathrm{H}-11$, & \\
\hline \multicolumn{5}{|l|}{$\mathrm{CH}_{3}$} \\
\hline 13 & $13.87^{\mathrm{d}}$ & $0.88(t, J=6.8)$ & & \\
\hline $13{ }^{\prime}$ & $13.80^{\mathrm{d}}$ & $0.83(t, J=7.1)$ & & \\
\hline $\mathrm{MeO}-2$ & 55.50 & $3.82(s)$ & & \\
\hline MeO-4' & 56.26 & $3.84(s)$ & & \\
\hline $\mathrm{MeO}-14$ & 52.30 & $3.87(s)$ & & \\
\hline HO-2' & & $11.26(s)$ & & \\
\hline
\end{tabular}

*Multiplicity of signals of carbon atoms deduced by comparative analysis of PND and DEPT- ${ }^{13} \mathrm{C}-\mathrm{NMR}$ spectra. Chemical shifts and coupling constants of hydrogen atoms obtained from $1 \mathrm{D}{ }^{1} \mathrm{H}-\mathrm{NMR}$ spectrum. The signals with same letter can be interchanged. 
and identified by a botanist from the Companhia Vale do Rio Doce. The voucher specimen (CVRD-368) is deposited at the Herbarium of the Companhia Vale do Rio Doce, Linhares, Espírito Santo State, Brazil.

\section{Extraction and isolation of the constituents}

Dried and powdered stem bark (615 g) was extracted at room temperature with $n$-hexane. The solvent was removed under vacuum to yield $2 \mathrm{~g}$ of residue. This residue $(2 \mathrm{~g})$ was chromatographed on a silica gel column $(75 \times 5 \mathrm{~cm})$ using $n$-hexane with increasing amounts of ethyl acetate. Eleven fractions of $200 \mathrm{~mL}$ each were collected. Fraction 3 (300 $\mathrm{mg}$ ), eluted with $n$-hexane-ethyl acetate (9:1), was rechromatographed as described above and ten fractions of 100 $\mathrm{mL}$ each were collected. Fraction $7(75 \mathrm{mg})$ eluted with $n$-hexane-ethyl acetate (80:20), containing the mixture of 4, 5, 6 and 7, was submitted to recycling HPLC to afford 4 $(40 \mathrm{mg})$ and a mixture of $\mathbf{5 , 6}$ and $\mathbf{7}(20 \mathrm{mg})$ as revealed by ${ }^{13} \mathrm{C}$-NMR spectrum. Fraction 5 (first column, $286 \mathrm{mg}$ ) was rechromatographed using the same procedure and the fractions $\mathbf{5}$ and $\mathbf{6}$ furnished the depside $\mathbf{1}(22 \mathrm{mg})$ after recrysttalization from $\mathrm{CH}_{2} \mathrm{Cl}_{2}-\mathrm{MeOH}(2: 1)$.

\section{Methyl 4'-O-methylarthonioate (1)}

M. p. $208-210^{\circ}$ C. IR $v\left(\mathrm{~cm}^{-1}, \mathrm{KBr}\right): 3424,1717,1686$, 1646, 1617, 1597, 1256, 1146. UV $\lambda$ (nm, MeOH): $210(\varepsilon$ 11943), 270 ( $\varepsilon$ 4793), 305 ( $\varepsilon$ 2558). ${ }^{1} \mathrm{H}-\mathrm{NMR}(400 \mathrm{MHz}$, $\left.\mathrm{CDCl}_{3}\right)$ : Table $1 .{ }^{13} \mathrm{C}-\mathrm{NMR}\left(100 \mathrm{MHz}, \mathrm{CDCl}_{3}\right)$ : Table 1. EIMS $m / z$ (rel. int.): Scheme 1.

\section{Acknowledgments}

This work was supported by a fellowship and grants from the Conselho Nacional de Desenvolvimento Científico e Tecnológico (CNPq) and by the Fundação Estadual do Norte Fluminense (FENORTE). The authors are also grateful to Reserva Florestal da Companhia Vale do Rio Doce (Linhares, Espírito Santo State, Brazil).

\section{References}

1. Hegnauer, R. In Chemotaxonomie der Pflanzen, Bond 8; Bickhauser; Berlin, 1989, p. 52.

2. Buckingham, J.; Donaghy, S.M., Eds. In Dictionary of Organic Compounds, Vol. 1, Chapman and Hall, New York, 1982, (5th edition), p. 442 (compound A-03500).

3. Reference 2, Vol. 4, p. 4097 (compound M-03937).

4. Geissman, T.A.; Crout, D.H.G. In Organic Chemistry of Secondary Plant Metabolism; Freeman, Cooper \& Company; San Francisco, 1969, p. 110, 111, 395, 396.

5. Reference 2, Vol. 5, p. 5511 (3,6-Di-O-methylether of T-03421).

6. Garcia, R.F.; Brown-Jr., K.S. Phytochemistry 1976, $15,1093$.

7. Mahato, S.B.; Kundu, A.P. Phytochemistry 1994, 37, 1517.

8. Chaurasia, N.; Wichtl, M. J. Nat. Prod. 1987, 50, 881.

9. Breitmaier, E.; Voelter, W. Carbon-13 NMR Spectroscopy: High-Resolution Methods and Applications in Organic Chemistry and Biochemistry; VHC; Weinheim, 1987, 3rd Edition.

10. Sanders, J.K.M.; Hunter, B.K. Modern NMR Spectroscopy - A Guide for Chemists; Oxford University Press; Oxford, 1993, 2nd Edition.

FAPESP helped in meeting the publication costs of this article 